\title{
Use of Psychological Techniques in Classroom Management with Arab context
}

\author{
Badia Hakim \\ King Abdulaziz University, Jeddah, Kingdom of Saudi Arabia \\ E-mail: badiahakim82@gmail.com
}

Doi:10.7575/aiac.alls.v.8n.2p.85

Received: 23/02/2017

URL: http://dx.doi.org/10.7575/aiac.alls.v.8n.2p.85

Accepted: 14/04/2017

\begin{abstract}
The said study focuses on the importance of effective use of psychological techniques in classroom management in Arab context. Pragmatic studies have established the effects of change in behavior on learning abilities of the students. This study scrutinizes the enhancement in investigation to confirm cognitive enhancement and stimulus among learners as it is significant so as to keep the discipline and boost the acquisition context in the class. The notion of the cognitive manner has dignity of uniqueness and inevitability in bringing about prime changes in the academic performance as well as behavior of the students. Psychological techniques have an impact on the course of academic performance of a student and determine the path of success in order to gain desired results. For this study several psychological techniques were focused that can effectively be applied in the class controlling. This research also focused on the mapping out of the relationship between learning and discipline. The researcher observed two classrooms at the English Language institute (women's main campus) having same instructors for two modules. This study describes the lethal effects of bitter behavior with the learners who produce a context where students' behavior turns aggressive and learning abilities get negatively affected. Though, this is imperative and of integral importance to evaluates the efficacy of cognitive procedures in class controlling and order. Further, the cognitive requirements of the learners should be observed so as to gauge the correct measures taken to enhance the learning process. Involving peer checking at this level to observe and get more reliable and valid result is also a great scenario.
\end{abstract}

Keywords: ELI, Psychological, cognitive, stimulus, classroom controlling, motivate, procedure, teacher

\section{Introduction}

The literal definition of Psychology is the study of behavior in its simplest form. The psychologist is eventually trying to formulate the laws of compact human behaviors. As per psychology rules, the living kinds, role, practice or treat based on the set rules of nature for them. Correspondingly, when behaviors are studied as a subject, they are denoted as the "Educational Psychology".

As stated by G.L. Anderson (1949), "Educational psychology is a subject that focuses on the study of an area or field of knowledge, a set of applications of laws and principles that relates knowledge to a social process, a set of tools and techniques, and a field for research".

Educational psychoanalysis can be considered a separate principle with a stable set of approaches, procedures, issues and manners.

Through the application of the scientific theory, educational psychoanalysts theory their issues with a scientific approach and solve them by using scientific methods. In research field, new research manners and differentiations of such manners and rules are evolved with the course of time. In relation to Educational psychology there are multiple frame works that are utilized in the field of education and while collecting the data for the related facts. For the current study the focused and chosen psychological techniques the ones that are frequently applied in class controlling, such as stimulus, boost procedures and instructor learner relationship.

Education cognition gives some ways to assure the productive instruction manner with achievement and acceptable outcomes. In current era of complicated students' behaviors, classroom management has attained all the prime attention of the teachers and education psychology is the only tool that provides effective procedure to keep the order and improve instruction process. An immense amount of research has been conducted by many researchers on the controlling issue and the influence of psychological behaviors to resolve the frequently encountered behavioral problems. A brief introduction of this situation has been presented in the said article by relating the facts and figures collected in this research.

\subsection{Hypothesis}

The effective Psychological techniques used by the instructor have a robust control over the motivation or demotivation of the students and on achieved outcomes. 
The below cases are the research questions created as the purpose of the this research;

- What are the focused psychological techniques that are frequently used in the classroom for students' motivation or demotivation?

- How Psychological techniques can be utilized in effective manner to help student gaining the accepted outcomes?

- What are the essential cognitive problems behind the misbehavior of the students in the learning process?

1.3 Study Aims

- The below items are the aims of the research:

- To assess the procedures and the way they influence students' treatment.

- To specify the prestige and reliability of the learning context in relation to the applied procedures.

- To reconnoiter the students' motive as teacher insinuates the cognitive procedures.

1.4 Delimitations of the Study

The below cases are the delimitations of the research

- The scholar used students from four sections of level 104 to conduct her research.

- There were two classrooms per module selected to implement the research plan and collection of facts.

- The study was conducted at the English Language institute women's' main campus - KAU.

\section{Literature Review}

Various cognitive theorists have accomplished investigation on the elements influencing the general context of the learning class. Yet there exist numerous cognitive theorists putting their efforts to reconstruct some thinkers so as to reconnoiter the cognitive essence of learners and their essential requirement in this regard. There is a great contribution of many psychologists who have contributed a lot for the formulation of theories that are effective in maintaining discipline and learning environment in a classroom. These psychologists have put collective efforts in the construction of these theories regarding the psychological behavior of the students.

As a matter of fact, Jones (1979) accentuated the need of reinforcement in order to simplify learning for students and minimize behavioral disruption in the course of learning. The effects of reinforcement show more improvement in facilitating the learning process and minimizing behavioral disruption.

As stated and emphasized by Herbert Grosman, "there are certain basic needs of the students that should be fulfilled in order to build the character of the responsible members of the society. On the same pattern, Richard Curwin and Allen Mendler revealed multiple global causes of misbehavior that elaborate the root cause of the learning context disturbance.

Anderson relied on the requirement of stimulus in forming the personality of a learner and needs for inner and outer stimulus to turn the instruction process into a type of practice that is considered-provoking and pleasing.

In the same environment, Meichenbanm (1977) contributed his research findings as 'cognitive behavior modifications' as the fundamental practices of self-control for the accepted outcomes in achieving a good behavior and productive academic results. Robin, Scheider and Dolnick (1976) also presented their turtle technique that of is also an effective contribution towards the behavior modification techniques.

All the above mentioned researchers have contributed immensely by doing research in order to facilitate learning process and improve the level of academic achievement. Researcher through the said study has strived to order these cognitive rules as a collection of active cognitive procedure for influential classroom control. These techniques have effectively been utilized by the teachers in maintaining a perfect classroom management arena and also to achieve the acceptable outcomes in treatment and colleges.

\section{Research Methodology}

The mentioned study lies in the group of qualitative study having the chief concentration on the case research without involving any statistics. This method of qualitative research has been chosen only to test this process of behavioral study on a deeper level because the qualitative research provides a source for the study of any phenomenon extravagantly and helps to explore the concealed motives and approaches.

For detailed investigation of the null hypothesis, the researcher has selected two classrooms per module from level 104 with the female students of the same age group taught by a qualified instructor. Each classroom was projected to analyze the events and the way the teacher includes these procedures to get proper valid results.

The researcher repeated this test phenomenon on two more similar state classes from level 104 in the next teaching module. The reason to repeat the techniques on two different sections was to confirm the reliability and validity of the used techniques and to make their results more authentic. 
Almost fourteen weeks ( 7 weeks per module) have been observed by the scholar to see this event in essentially academic contexts. The scholar's purpose is not getting included in the class reading. She only observed the phenomena to develop objective opinion. Later at the end of second module of study pattern, the researcher compared the results of 4 sections (two sections per Module)

The scholar falls into the group of longitudinal study as 14 weeks' consideration have been included in an essential context to consider the way cognitive procedures assisted students and the instructors to comprehend any event and do well in coming cases.

\section{Results \& Discussion}

The biggest challenge for the instructors predominantly the novice instructor is to maintain classroom discipline. The most revolting behavioral issues faced by the instructors could be murmuring, humming and producing turmoil, discussing, poking fun at sleeves or use of mobile phones. All these issues are not only the cause of disturbance in the classroom on the part of students, but it also obstructs the regular teaching process and smooth learning. The immediate response of an instructor to such a disturbance may invite disappointing reactions; screaming, shouting or discouraging the students. But, the output of punishment manners are again destroying; it gives aggression in the learner and bad effect towards the instructor. In order to handle such ugly situations in the classroom requires implementation of suitable discipline strategies and management techniques to overcome troubles in this regard. At this point, some light can be shed on the use of the right rationale for an effective management strategy.

Most importantly noted fact is that insignificant or indeed no learning can be observed to happen in such a classroom that is lacking in discipline. Implementation of the right management strategy to such classes is quite time consuming but is an obligatory act. Moreover, the effective management strategy introduces a deep sense of responsibility and self-control among students.

Additionally, use of an effective classroom management strategy supports the instructors and administrators to shelter them from getting blamed for being a cause for failure or any other academic damage. This phenomenon also helps to decrease the unwanted focus on an instructor and instruction process happens with more achievement.

The main aim of the method is to observe the requirements of the learners, in order that they can create finer outcomes. Supporting the framework of right techniques in order to meet the requirements of the learners improve their acquisition skill and fond of the course. In relation to the same ideology, Herbert Grossman accentuates on the main requirements of the learners that must be observed so as to create responsible members of the community. Certain rudimentary essentials should be kept in mind in order to observe the requirements of the learners which are significant to keep order in the course; one of the basic needs of the student is treating them with love and care. This necessitates the availability of an environment in classrooms that is fair, humane, unswerving free of partiality and without critique. Learners achieve speedier in a proper context and it may be considered that they will achieve to show the same behavior towards others also. Keeping this situation not only decreases to the order in the course, but also stimulates positive approach and treatment of the learners towards the teacher as well. The negative approach of indifference among the instructors and the learners impedes the process of advancing acquisition and results in the addition of pollution to the relationship between them. Learners that are treated in a caring manner by the instructor with the use of right techniques accept some features without difficulty that contributes to them to achieve self-esteem and comprehending one's own ability.

A huge amount of discussion can be done on the importance of students' needs, but in the current study we restrict ourselves to the cognitive facets of the learners. In relation to the same fact, Richard Curwin and Allen Mender demonstrated myriads of objective reasons for mistreatment which showed the foundation of the class turmoil. They concentrated on the cognative distress in learners and its motives. They commented that following reasons can contribute to enhance the classroom dissension

- Unstable house atmosphere

- throw-away the community discourse

- private assault on one's esteem or the superficial and physical face

- emotions of weakness

Mistreatment from a learner can be always an outcome of multiple stimuli with numerous psychoanalytic imprints.

An indifferent attitude of a teacher's can provoke misbehavior and enhances the chances of reported cases of aggression. Another situation could be an odd reaction from the students to gain attention due to feeling unattended in the classroom. Additionally, psychological anguish grasps the student's mind as he/she experiences emotions of weakness and fears of defeat. In a stressful situation like this, the student hardly follows the shapes of acquisition or avoids endangering in acquisition. The other challenging situation befalls when teacher starts acting as a "buddy" to learners. Here, the theory of being honored becomes ambiguous.

Risky discipline issues arise when students start viewing the teacher as their buddy rather than authority. These out of norms factors hamper the cognitive position of a learner and make them mistreat in a manner they feel easy with. The correct manner to behave such cognitive depression among learners is the sufficient application of cognitive procedures to stimulate interest in them and to eliminate the defiant attitude towards the instructors. 
Use of correct psychological treatment brings more focus towards the process of instructions and learning and replaces behavioral disorders among students. The psychological infirmity in learners produces passiveness, hyperactivity and results in weak academic practice. The cognitive trauma also decreases towards having fewer relations with the friends and relatives, misbehaving and disobeying the adults and poor relationships with parents.

There is an immense research has been done on a variety of motivational characteristics of students and how this psychological anguish can bring a change in the behavior and attitude towards learning process. The most important step towards achieving this target is to invite involvement and responsibility for learning without creating disturbance and misbehavior in the class. There is a famous proverb suitably quoted to this state; "you can lead a horse to water, but you can't make it drink".

Likewise, learners can be sent to research but they may not be boosted to achieve and keep on conformity and balance in principle. Without maintaining a mental inclination, there may be lesser to be studied and less to be seen under the frame of regulations and principles at an institute.

As quoted by Anderson, "Learning will progress best if well motivated". In the same relation, Harris stated that the issue of stimulation is an essential matter both to the achievement and to the class manners. Kelly stated that stimulation is the essential case in the effective control of the acquisition process. Ames (1919) reinforced that motivation is a psychological technique as frequently well thought out and practiced towards achieving the aims in education. This procedure may be materialized to train the students in terms of behavior. The effective use of motivation in academic arena has a stronger impact and is theoretically a vital idea.

As studied and stated by (Nolen1988) students with well oriented learning techniques;

- Get engrossed in more attended behavior to achieve better acquisition and investigating manners.

- Give much quality and quantity of work for the sake of learning

- Show more self-confidence s as better learners

Implementing the effective management techniques and maintaining discipline is conditioned with psychological need of the students. Mockery and cynicism is the bottle neck in getting the psychological techniques implemented. Any act of embarrassing or humiliating a student in public may outcomes in treatment disruptions and obvious anger and the learner is made react negatively and helps for the mistreatment. Accomplishment of such unsuitable behavior creates unwillingness, hinder, undecidability and lack of self- esteem and self-respect. This matter may make a learner leave educational practice and create a negative approach against laws and principles as a reaction. To encourage such an act, the best possible technique to be used is to stimulate a learner for aims in order that the responsibility of acquisition and keeping behavior is supported by the student.

Motivation rejuvenates and leads to acceptable learning behavior. Stimulation is a mixture of various elements like requirements, inquisitiveness and concentration. Further subcategories of motivation are inner and extrinsic stimulation. As stated by Deci \& Ryan 1985, Reeve 1996, "intrinsic motivation is the natural tendency to pursue and overcome challenges as we follow personal interests and drill existing capabilities. An intrinsically motivated student doesn't look for the rewards and punishments because the learning itself becomes rewarding in such cases." In such cases, the student also upholds self-control in order to access the chance and does not disorient from the set course of learning. Brophy 1988, Deci \& Ryan 1996 strongly enforced that teachers must encourage and foster intrinsic motivation among their students. Opposite to that, if a student shows some gestures to achieve a better mark, to make someone glad, to avoid being degraded, this is a complete reflection of extrinsic motivation. This also labels the fact that the student is actually not involved in the activity; but is only concerned about the objective gains. In both items of inner or extrinsic, stimulation always helps achieve the classroom order. As defined by Jones-1979, Discipline most obviously regarded is the practice of making simple class regulations that make the achievement easy and curtail distraction.

Disturbance causing students are the ones who often show lack of stimulation ending to demonstrate negative approach, weakness and shortage of interest in the course. Madsen, Becker and Thomas (1968) reinforced that teacher can achieve an improvement in student's behavior by overlooking rule-breaking acts and admiring learners that are following the principles. Class control is not merely shaped by this admire and lack of admire technique, but it supplements the overall better behavior. McGoey \& DuPual 2000; Pfiffner \& O'Leary, 1987 stated that the disruptive behavior is kept on as instructors apply positive elements (mainly admiring) as their essential class control strategy. The praise remunerated to the students supports the better behavior in return and it is always a pure attempt to boost learners in order to achieve advancing outcomes. This is also stressed by some cognitive theorists that the application of admire inclines the learners to concentrate on acquisition to get praise rather than acquisition for its own sake. Learners keep a separate relation with their instructors and they require to be thanked and admired. Boosting is one of the outstanding practiced psychological techniques that can effectively be applied to keep order in the class as well as to accomplish better acquisition.

The best manners for accepted treat involve stimulation, boosting, programmed teaching, admire and acceptance and self-specification. Boosting is not sometimes sufficient in its efficacy on the learners and it may overlook the intimidated behavior. Though, reinforcement has dynamic results when it is unswervingly utilized to the target learners for more pore outcomes. It may contribute to enhancing the academic activity and acceptable treatment as well. 
Instructors also lure a tough relation with the learners stipulating the activity rules which must be achieved. This intelligent 'Exigency contracting' may be used to achieve the desired treatment in practice and in academic activity. This application of cognitive method drafts a relation between the instructor and the learner and proclaims the more proper self-control and self-management. Weakly stimulated learners can be tapered simply for the accepted outcomes. As described by Meichenbanm-1977, self-control skills are effective tools for behavior modification. He regarded these skills as 'Cognitive Behavior Modification'. There are five levels of such theory as described by Meichenbanm;

- an adolescent forms a task while speaks out

- The learner does the task when he speaks out self- teaching loudly.

- The learner does as per pattern-teaching.

- The learner murmurs self-teaching while accomplishing the task.

- The student performs the task under self-guidance through speech.

The said approach deals with the isolated learners by stimulating them to cooperate with their reviewer, helps learners to get more actively creative and teaches them aggression control strategies.

The 'Turtle' technique of Robin, Schneider and Dolnick (1976) enforces "teachers to instill violent students to adopt a turtle position when upset. They learnt to place their heads on the desk with closed eyes and clench fists. This activity defuses them to delay inappropriate behavior and empowers them to think about the problem usefully." This is not mandatory to adopt a turtle position; the main idea is to deferral whims and responses. Likewise, the 'Think Aloud' strategy devised by Kamp \& Dash (1981) is also intended "to train students to emerge with cognitive development to direct their social behavior and to overcome problems." McLaughlin 1976, O'Leary \& Dubey 1979 stated that these "cognitive skills of self-control are auspicious, both as instructional techniques and therapy for students with emotional or behavioral problems."

Dreikurs (1968) has described the acts of behavior issues as self-justifying practices by the learners that are dispirited, discouraged or sidelined. He also recommended that the way instructor can investigate the aim of commotion produced by the learners and the way to observe their cognitive requirement. There is a lot of argument from various psychologists regarding the reason and efficacy relation between the practices of disregarding the rules, misbehavior and the motives.

\section{Conclusion}

Through extensive studies and reviewer controlling it has been chiefly demonstrated that class control is a vital zone in effective learning and behavioral problems that slows down the teaching and acquisition process. Being demanding and applying tough penalty causes more hurt than benefit. The best feasible method of achieving the needed outcomes is to direct the class applying cognitive procedures like influential acquisition context, boosting the approach of instructors, stimulation, forming the desired behavior and individual scrutiny. Use of all these techniques claims symbiotic accomplishment in class control. These encompass respect for learners' uniqueness, the skill of realizing and observing their requirements, relying on directing rather than power-expression and general humanistic values.

Cognitive procedures are methodical, regulated strategy which can help a lot in order and the teacher can get predicted the outcome if they us those procedures in a systematic and influential manner to stimulate their students.

\section{References}

Ames, C., \& Ames, R. E. (1984). Research on motivation in education: Vol. 1. Student motivation. San Diego, CA: Academic Press.

Ames, C., \& Ames, R. E. (1985). Research on motivation in education: Vol. 2. The classroom milieu. San Diego, CA: Academic Press.

Anderson, L., Evertson, C., \& Brophy, J. 1979). "An experimental study of effective teaching in first-grade reading groups." Elementary School Journal 79, 193-223.

Anderson, L., Evertson, C., \& Emmer, E. (1980). Dimensions in classroom management derived from recent research. Journal of Curriculum studies, 12(4), 343-356.

Brophy, J. (1979). "Teacher behaviour and its effects." Journal of Educational Psychology, 71, 733-750.

Brophy, J. (1981). "Teacher praise: a functional analysis." Review of Educational Research 51: 5-32.

Brophy, J., \& Evertson, C. (1976). Learning from teaching: a developmental perspective. Boston: Allyn \& Bacon.

Brophy, J., \& Evertson, C. (1978). Context variables in teaching. Educational Psychologist, 12. 
Camp, B., \& Bash, M. (1981). Think aloud: increasing social and cognitive skills-a problem-solving program for children, primary level. Champaign, Ill.: Research Press.

Dreikurs, R. (1968). Psychology in the classroom: a manual for teachers (2d ed.). New York: Harper \& Row.

O'Leary, S., \& Dubey, D. (1979). Applications of self- control procedures by children: a review. Journal of Applied Behavior Analysis, 12.

McLaughlin, T. (1976). Self-control in the classroom. Review of Educational Research, 46, 631-663

Meichenbaum, D. (1977). Cognitive-behavior modification. New York: Plenum.

Meichenbaum, D., \& Goodman, J. ( 1971). Training impulsive children to talk to themselves. Journal of Abnormal Psychology, 77.

Robin, A., Schneider, M., \& Dolnick, M. (1976). The turtle technique: an extended case study of self-control in the classroom. Psychology in the Schools, 13, 449-453. 